\title{
The Stability of Prime Money Market Mutual Funds: Sponsor Support from 2007 to 2011
}

\author{
Steffanie A. Brady \\ Ken E. Anadu \\ Nathaniel R. Cooper
}




\title{
Risk and Policy Analysis Unit Working Paper Series
}

\author{
Federal Reserve Bank of Boston
}

\section{The Stability of Prime Money Market Mutual Funds: Sponsor Support from 2007 to 2011}

\author{
Steffanie A. Brady, Ken E. Anadu, and Nathaniel R. Cooper*
}

August 13, 2012

*The authors would like to thank Patrick McCabe of the Federal Reserve Board of Governors and Patrick de Fontnouvelle, Kimberly DeTrask and Eric Rosengren of the Federal Reserve Bank of Boston for their input to this paper. They are also grateful to Maria Onaindia and Peter Jones for their contribution to the data gathering effort. The views expressed in this paper are those of the authors and are not necessarily reflective of views at the Federal Reserve Bank of Boston or the Federal Reserve System. Please address correspondence to Steffanie A. Brady at Steffanie.Brady@bos.frb.org 


\section{Overview}

It is commonly noted that in the history of the Money Market Mutual Fund (MMMF) industry only two MMMFs have "broken the buck," or had the net asset value per share (NAV) at which they transact fall below $\$ 1$. While this statement is true, it is useful to consider the role that non-contractual support has played in the maintenance of this strong track record. Such support, which has served to obscure the credit risk taken by these funds, has been a common occurrence over the history of MMMFs. This paper presents a detailed view of the non-contractual support provided to MMMFs by their sponsors ${ }^{1}$ during the recent financial crisis based on an in depth review of public MMMF annual SEC financial statement filings (form N-CSR) with fiscal year-end dates falling between 2007 and 2011. According to our conservative interpretation of this data, we find that at least 21 prime MMMFs would have broken the buck absent a single identified support instance during the most recent financial crisis. ${ }^{2}$ Further, we identify repeat instances of support (or significant outflows) for some MMMFs during this period such that a total of at least 31 prime MMMFs would have broken the buck when considering the entirety of support activity over the full period.

\section{Background}

On September 16, 2008, the Reserve Primary Fund (the "Reserve Fund”) broke the buck due to its \$785 million (1.2\% of net assets) exposure to Lehman Brothers debt securities. This event served to remind investors that investments in MMMFs can in fact lose value. The Reserve Fund's losses also led to its closure and a prolonged liquidation process ${ }^{3}$ - a significant cost for investors who value both preservation of principal and liquidity. Observing the fate of the Reserve Fund, investors began to exit other prime MMMFs (i.e., MMMFs that hold instruments such as commercial paper, certificates of deposit, and other forms of short term paper that carry credit risk) that might also have exposures to Lehman or to other issuers with a heightened risk of default or market value decline. ${ }^{4}$ By exiting quickly, investors protected themselves not only from incurred losses yet to be recognized but also from liquidity strains arising from other investors choosing to redeem. These incentives to "run" were heightened by the lack of any cost or other penalty for redeeming an investment in a prime MMMF.

The run on prime MMMFs caused further disruption to already stressed short term corporate credit markets. Though many of the redemptions from prime MMMFs flowed into Treasury and Government MMMFs, and thus MMMF assets in aggregate fell less sharply than those of prime MMMFs, the Treasury and Government funds were not eligible to purchase many of the corporate issues that prime MMMFs were selling or ceasing to roll over. Unprecedented emergency facilities established by the Treasury and Federal Reserve ultimately slowed redemptions from prime MMMFs and helped maintain liquidity in the short term corporate funding markets. ${ }^{5}$

\footnotetext{
${ }^{1}$ Sponsors are defined as the MMMFs' asset management firms and their parents and affiliates.

${ }^{2}$ As later discussed, the estimate of 21 funds is based on conservative assumptions of asset levels and, by excluding guarantees, does not factor in the full range of support received by prime MMMFs.

${ }^{3}$ Investors were expected to recover approximately 99 cents on the dollar inclusive of interest accrued during the liquidation process. A Reserve Primary Fund press release dated December 3, 2008, noted that shareholders had received approximately $80 \%$ of their investment proceeds as of that date. http://www.primary-yieldplusinliquidation.com/pdf/PressReleasePrimDist22008_1203.pdf

${ }^{4}$ See McCabe (2010), which finds that, "greater portfolio risk, as measured by higher gross yields in the year prior to September 2008, was associated with significantly larger outflows during the run."

${ }^{5}$ See Duygan-Bump, Parkinson, Rosengren, Suarez, and Willen (2010).
} 
The Reserve Fund was only the second MMMF to break the buck since the SEC adopted rules governing these funds in 1983, with the first being the Community Bankers US Government Fund in $1994 .{ }^{6}$ Both funds had losses significant enough to cause them to break the buck and sponsors that were unable to provide non-contractual support to prevent the losses from being passed on to shareholders. However, it was the lack of sponsor support for these two funds that was more unusual than the underlying losses suffered, as credit events have impacted many more than two funds in the history of the MMMF industry. ${ }^{7}$ The remainder of this paper discusses the credit losses suffered between 2007- 2011 by MMMFs other than the Reserve Fund, and the related support provided by sponsors to offset these losses.

\section{Description of Data and Methodology}

\section{Identifying and Quantifying Instances of Support}

Figures 1 and 2 present information on support provided to prime MMMFs from fund sponsors in the form of a cash contribution (with no resulting benefit to the sponsor) or an outright purchase of distressed securities at above-market prices, collectively referred to hereafter as "direct support”. In the case of a security purchase, the direct support amount is the difference between the purchase price and the estimated market value of the purchased security as disclosed in the MMMF's financial statement filing; it is not the full purchase price of the security.

While not considered here, purchase prices would be relevant in considering a sponsor's ability to support since a sponsor would need adequate liquidity for the purchase in addition to the ability to absorb related losses. Notably, the Credit Suisse Institutional Money Market Fund Inc. disclosed sponsor purchases in the amount of $\$ 5.69$ billion during the year ended December 31, 2007. In December 2007, Janus Capital management purchased Stanfield Victoria Funding LLC positions from two Janus funds for over \$100 million. Asserting that amortized cost approximated fair market value, neither MMMF disclosed any related losses or contributions from the sponsor, and accordingly, related support amounts are not included in our data set.

It is also important to note that our definition of support is narrow and excludes certain instances of sponsor intervention to protect MMMFs from losses. Specifically, direct support excludes support in the form of Capital Support Agreements (CSAs) and/or Letters of Credit (both of which provided guarantees on individual or a portfolio of securities) that were not drawn upon - even where such facilities were important in maintaining the market value NAVs of the funds. ${ }^{8}$ Although such guarantees are an important form of support, placing a value on these agreements can be difficult and excluding them ensures that no support is double counted, since many guarantees later resulted in purchases of debt securities subsequent to their default. It also results in a lower reported frequency and value of support.

Figure 1 presents individual "instances” of support. Each financial statement period in which support was disclosed for a fund is considered an instance in Figure 1, even where there may have been multiple

\footnotetext{
${ }^{6}$ Large losses associated with its adjustable-rate derivative holdings caused the Community Bankers US Government Fund to break the buck.

${ }^{7}$ The August 2010 Moody's report, Sponsor Support Key to Money Market Funds, notes various credit related events triggering sponsor support since 1989.

${ }^{8}$ These agreements increase the reported value of the portfolio, resulting in a NAV per share that does not reflect the full market value declines in all or some of the underlying securities. The impact is recorded as a liability on the books of the sponsor.
} 
support events during the fiscal year. ${ }^{9}$ Figure 2 aggregates the instances for each fund. Support instances were identified through a detailed review of annual SEC financial statement filings on Form N-CSR, Certified Shareholder Report of Registered Management Investment Companies, for 341 funds ${ }^{10}$ with year ends falling between 2007 and 2011. As funds have different year ends, the earliest month covered was April 2006 and the latest October 2011. Accordingly, all fund financials reviewed would cover the common period of January 2007 through January 2011.

The financial statements reviewed were subject to an independent audit and include disclosures specifically quantifying the value of the direct support. For security purchases, this disclosure includes the amount by which the purchase price exceeded fair market value (or the two figures necessary to calculate the difference), in all but one case. ${ }^{11}$ Accordingly, full reliance was put on these disclosed figures when they were available, and assumptions regarding the fair value or the value of support were not necessary in these cases.

Previous work has explored or referenced instances of fund sponsor support including that of Baba et al. (2009), Kacperczyk and Schnabl (2012), McCabe (2010), and Moody’s (2010). However, this paper is unique in presenting a complete data set of direct support instances and related amounts formed through a detailed review of the financial statements of all prime MMMFs. We observe that some past work has evaluated support by reviewing funds that received SEC no-action letters related to affiliate transactions. While a good general proxy for support, SEC no- action letter requests were not required for all forms of fund support ${ }^{12}$ and the request for and issuance of a no-action letter does not obligate, in any way, the recipient(s) of a no-action letter to engage in the transaction(s) for which no-action relief was requested or granted. We identified 39 funds for which direct support was provided and a no-action letter was not requested. We also noted numerous funds for which a no-action request was made but no support was subsequently disclosed. By reviewing the financial statements, we obtain additional information on the nature and amount of support on an ex post basis. Finally, as previously noted, our data set focuses only on direct support to U.S. prime MMMFs and includes the review of SEC filings for an extended time period covering support events occurring as late as fiscal years ended October 31, 2011, which makes a comparison to other work that includes guarantees (which were not utilized) difficult.

\section{Comparisons of Support Data to Asset Levels}

This paper is the first to explore in detail the relationship of support provided to the size of the supported funds. Figures 1 and 2 present information on the net assets under management (AUM) of each fund in order to assess the relative magnitude of sponsor support received. There were three challenges to address in collecting asset data. First, it was not always clear exactly when reported support occurred.

\footnotetext{
${ }^{9}$ For example, the August 28, 2010 financial statements for the Columbia Cash Reserves Fund disclose sponsor purchases made by NB Funding Company LLC., an affiliate of Bank of America of securities, of five issuers on four dates during the period, but are counted as a single instance.

${ }^{10}$ The population reviewed was developed by merging the list of funds reporting to iMoneyNet as of January 2007, requests for related no action letters from the SEC, and funds that filed SEC Form N-MFP, Monthly Schedule of Portfolio Holdings of Money Market Funds, in the first required reporting period.

${ }^{11}$ As noted in Footnote 2 on Figure 1, a Columbia Fund lacked the detailed disclosures found in other funds and an assumption about the support amount had to be made based on related financial statement disclosures.

${ }^{12}$ Rule 17a-9 provides an exemption from the affiliate transaction restrictions of Section 17(a) of the 1940 Act for the purchase (by an affiliate or an affiliate of an affiliate) of a security that is no longer an "eligible security" under Rule 2a-7 from a MMMF if the purchase price is paid in cash and the purchase price is equal to the greater of the amortized cost of the security or its market price (in each case including accrued interest). See 61 Fed. Reg. 13956 (Mar. 28, 1996).
} 
For example, SLAT Prime Obligation Fund disclosed a variety of asset purchases occurring in the year ended June 30, 2009, but did not disclose transaction dates. Second, even if the date of the support was disclosed, in many cases that date represented when the sponsor chose to provide direct support, but the direct support may have been preceded by indirect support such as guarantees that were important in stabilizing the NAV, reassuring investors and preventing runs. Finally, for some funds, AUM data were not available daily or even monthly for the periods reviewed, and thus a perfect match could not be obtained even if the exact support date was known.

Given all of these challenges, Figure 1 includes the highest AUM figure for each fund over the reporting year per both SEC annual and semiannual filings and voluntary filings by the fund with iMoneyNet, as applicable. Using the highest available AUM figures provides the most conservative view of the relative magnitude of each identified instance of direct support. For 28 instances covering 18 funds for which iMoneyNet data were not available, the AUM data on Figure 1 represent the highest of the beginning, semiannual, or ending AUM figures for the year when the support occurred, as disclosed in the SEC filings. For the remaining instances and funds, the AUM amount reported on Figure 1 is the highest of either these three figures or the daily assets reported by iMoneyNet.

Figure 2, which aggregates support by fund, presents the ending AUM figures for the last presented reporting period. This portrays the total loss amount for the fund over all periods relative to the ending AUM figures as if no fund support had been provided in any period and thus losses had accumulated in the fund. Accumulating the support amounts assumes that absent sponsor support, the fund would not have been able to recover any of the losses that prompted the support through an offsetting realized gain.

\section{Findings and Observations}

The data suggest that during the period from 2007 to 2011, sponsor support was frequent and significant to many of the supported funds. Direct support alone totaled at least $\$ 4.4$ billion, provided to at least 78 of the 341 funds reviewed. Support for these 78 funds occurred in 123 instances with 32 funds receiving support in multiple reporting periods. ${ }^{13}$

\section{Drivers of Support}

Support was largely driven by holdings of defaulted structured investment vehicles and Lehman obligations in 2007 and 2008. Figure 3 presents a list of defaulted securities referenced in at least one financial statement of the supported funds. Figure 4 presents the driver of support disclosed for the 21 funds with instances over $0.5 \%$ of AUM, as disclosed in the fund financial statement or in a related noaction letter. In some cases in the broader population of instances, the reason for support is not always specified in the financial statements beyond generic terms such as "due to realized losses of the fund", "to maintain the mark-to-market net asset value", or "to ensure the Fund maintained the highest credit rating possible.”

It is important to note that MMMFs are still susceptible to risks related to portfolio holding downgrades or default, even subsequent to the 2010 SEC amendments to Rule 2a-7, promulgated under the Investment

\footnotetext{
${ }^{13}$ One instance is also identified in which support received by a Victory fund was returned to the sponsor, although the fund ultimately provided support again in order to strengthen the NAV per share.
} 
Company Act of 1940. ${ }^{14}$ If the current rules were in place in 2007 and 2008, prime MMMFs could still have held the distressed asset-backed commercial paper and Lehman debt securities that triggered support for many funds and the break the buck event for the Reserve Fund. Indeed, Lehman debt maintained the highest short term ratings up through the time it filed for bankruptcy. ${ }^{15}$ And recent sponsor behavior indicates that support is still a likely event in the face of such credit events or uncertainty. Although no MMMF holdings have defaulted since 2008, two Northern Trust funds ${ }^{16}$ disclosed the purchase of downgraded Eskportfinans ASA paper from their portfolios by the sponsor in November 2011, amid a threat of a downgrade to the funds' own ratings.

\section{Timing of Support}

Although the triggering market events occurred over the two years at the beginning of our review period, direct support continued in later years as well. In some of these instances, fund sponsors delayed direct support by putting in place multi-year guarantees. For example, the SDIT Prime Obligation Fund, which only shows support for the fiscal year ended January 31, 2010, disclosed that on November 8, 2007 it entered into a CSA with SEI Investment Company providing that SEI would cover any losses realized on sales of securities that caused the mark to market NAV of the fund to fall below $\$ 0.9975$. In other instances, sponsors allowed the fund NAVs to initially absorb small losses that were not large enough to cause the fund to break the buck, only to later provide support. Accordingly, many of the instances of support towards the end of the five year period reviewed were a small percentage of the funds' AUM. In these cases, it is likely that the fund support was motivated by the anticipation of enhanced SEC disclosure requirements, including monthly publication of the fund's market value NAV, or to avoid more burdensome compliance procedures mandated by the SEC for funds with market value NAVs below \$0.9975. This was summarized well in the January 31, 2011, filing for the Wells Fargo MMMFs receiving support for that period:

"On November 29, 2010, the following Funds received contributions from Funds Management in order to support the mark-to-market net asset value of each Fund. This action was voluntary and was not necessary to maintain the $\$ 1.00$ per share net asset value of these Funds at which shareholders transact, but was taken to address potential shareholder concerns due to regulatory changes that require all money market funds to make public their mark-to-market net asset values out to four decimal places."

\section{Significance of Support}

Many of the support instances observed over the full period are significant relative to the fund's NAV, and at least 21 funds received support exceeding $0.5 \%$ of the fund's AUM, an amount large enough to

\footnotetext{
${ }^{14}$ Amendments to Rule 2a-7, adopted by the SEC in February 2010, include: reduced portfolio Weighted Average Maturity (WAM) limit (from 90 to 60 days); a new portfolio Weighted Average Life (WAL) limit of 120 days; enhanced portfolio disclosure requirements; periodic stress testing requirements; limits on second tier securities; daily (10\%) and weekly (30\%) liquidity requirements; suspension of redemptions; "Know Your Investor" procedures. http://www.sec.gov/news/press/2010/2010-14.htm

${ }^{15}$ Although Rule 2a-7 limits MMMF investments to those that “present minimal credit risk," this term is not defined, and MMMFs are permitted to hold securities along a range of credit risk. This was also true at the time of the Lehman default, prior to the SEC's 2010 amendments.

${ }^{16}$ Northern Institutional Diversified Assets Portfolio and Northern Institutional Prime Obligations Portfolio.
} 
suggest that without support, the fund's NAV would have rounded to less than $\$ 1 .{ }^{17}$ Further, if multiple direct support amounts are taken in aggregate for each fund over the full period and compared to ending AUM, the number of funds with losses over $0.5 \%$ rises to $31 .{ }^{18}$ This calculation represents the accumulated losses funds would have suffered absent sponsor support, assuming that no realized gains could be recognized as offsets during the period.

These simple measures of support do not take into account two very important factors. First, if support had not been provided to the funds, it is likely that increased investor redemptions would have resulted and reduced each fund's AUM, thus magnifying the impact of the losses for remaining investors. ${ }^{19}$ Second, the use of a $0.5 \%$ threshold is conservative because it assumes that there are no unsupported losses in each supported fund. For example, if a fund had a total combined realized and unrealized loss of $0.7 \%$, support of only $0.3 \%$ would be enough to prevent the market value NAV of the fund from falling below $\$ 1.00$.

The largest support instance noted relative to AUM was the $\$ 336.8$ million, or 6.3\% of AUM, support to the Russell Money Market Fund. This entire amount was due to the purchase of the Fund's Lehman holdings, as noted in the following disclosure, "On September 14, 2009, the Lehman Securities were purchased by Frank Russell Company from the Fund at amortized cost of \$402,764,934 plus accrued interest of $\$ 775,756$." While such a large exposure seems inconsistent with the $5 \%$ concentration limit of Rule 2a-7, it is important to note that such limits are only in effect at the time of purchase. In addition, this Fund experienced significant net redemptions ${ }^{20}$ prior to the direct support action described above. Prior to the direct support event, the sponsor provided a guarantee on the security, which represented $6.7 \%$ of the portfolio value at October 31, 2008.

\section{Implications of Fund Support to the Sponsor}

This paper does not make assertions about the significance of the support to the sponsor, but rather our focus is on the impact of support to prime MMMFs and its potential to cause investors to perceive that prime MMMF portfolios are less risky than they actually are. It should be noted that a support amount as reported in this paper is not necessarily equivalent to a loss realized by the fund sponsor. Instead, in the case of a security purchase, it is indicative of the loss that would have been realized by the fund sponsor if it had disposed of the security on the same day that the purchase was made from the fund. If the sponsor instead chose to hold the security, the actual loss suffered could have been greater or less depending on subsequent market movements or the terms of the ultimate settlement of the obligation by the issuer. Additionally, in the case of a direct contribution, a fund could later reimburse the sponsor in full or in part, as was the case for the Victory Institutional Money Market Fund noted in Footnote 13 above.

\footnotetext{
${ }^{17}$ In fact, the smallest instances among the 21 cited were $0.61 \%$ and $0.62 \%$ of AUM. Pre-support NAVs for the two MMMFs would need to exceed $\$ 1.001$ in order for these amounts to not cause the MMMFs to break the buck. Review of prior financial statements indicate that such a buffer was likely unavailable at the time of support.

${ }^{18}$ The use of ending AUM is deemed appropriate given that even if a fund shrank during the year, all losses incurred during the year would remain in the fund and be shared by the remaining investors so long as the fund continued to redeem shares at a dollar.

${ }^{19}$ Based on behaviors observed in both the Fall of 2008 and Fall of 2011, it is likely that such redemptions would be driven by institutional investors, presumably due to their more active monitoring of the funds.

${ }^{20}$ At October 31, 2007, the fund had net assets of \$5,289 million, which fell to \$2,578million by October 31, 2008. Further subsequent redemptions led to the 14.1\% of AUM support amount disclosed on Figure 2 (Footnote 5).
} 
It is interesting to consider why a sponsor chooses to support a MMMF even though it is not contractually required to do so. Fund sponsors may be concerned about their reputation in the market place, loss of cross-selling opportunities, or the cost of potential investor lawsuits. ${ }^{21}$ We posit that fund sponsors may also choose to provide support because they initially underestimate the amount of support necessary to fully alleviate financial concerns in the funds. While the entirety of support is costly, the incremental cost at each point may appear worthwhile.

Regardless of the motivation, sponsor behavior observed through these support instances suggests that while the costs can be significant, the perceived benefits at the time of support were greater to most fund sponsors. Understanding both the significance to the sponsor and their motivations would be important in making judgments as to whether investors should reasonably expect this model to continue, as it is possible that the sponsor value proposition could shift, especially where necessary support amounts are large.

\section{Conclusion}

Investors in MMMFs choose these funds because of the stability and liquidity that they provide ${ }^{22}$. This is precisely why these investors are prone to run during a financial crisis when either or both of these product features may be compromised. If investor losses resulted from market events more frequently, it is possible that the investor base and level of interest in the funds today would be very different. But, as this paper shows, such outcomes are not frequent, as even in times when market events would have caused losses to many investors, the voluntary actions of sponsors has negated this impact.

It is unclear whether MMMFs, as currently structured, are really pass-through entities. Fund investors see no fluctuations in their share values based on changing interest rates or credit spreads. When fund losses materialize, it is usually the sponsors rather than investors who absorb them. And in the only recent example of investors being required to absorb a loss, a run was triggered on other funds that may have significantly impacted the broader economy absent government intervention.

If sponsor support were explicitly required and planned for, and all sponsors had the consistent ability to provide support, such a business model might not be viewed as problematic. But the current model is concerning in that it reinforces investor confidence in the stability of the product without the ability of all sponsors to consistently deliver.

\footnotetext{
${ }^{21}$ For example, in addition to many other claims, there were at least nine claims against the Reserve Fund for breach of fiduciary duty. Many individual lawsuits also noted that the investment strategy of the fund was incongruent with its stated investment objective and its marketing as a safe investment option.

${ }^{22}$ Fidelity Investments (2012). Association for Financial Professionals (2012).
} 


\section{References}

Association for Financial Professionals, “2012 AFP Liquidity Survey”, July 2012. http://www.afponline.org/pub/pdf/2012 AFP Liquidity Survey Introduction.pdf

Baba, Naohiko, Robert N. McCauley, and Srichander Ramaswamy, “US dollar money market funds and non-US banks,” BIS Quarterly Review, March 2009. http://www.bis.org/publ/qtrpdf/r_qt0903g.pdf

Duygan-Bump, Burcu, Patrick M. Parkinson, Eric S. Rosengren, Gustavo A. Suarez, and Paul S. Willen, "How Effective Were the Federal Reserve Emergency Liquidity Facilities? Evidence from the AssetBacked Commercial Paper Money Market Mutual Fund Liquidity Facility," 2010. Federal Reserve Working Paper. http://www.bostonfed.org/bankinfo/qau/wp/2010/qau1003.pdf

Fidelity Investments, “The Investor's Perspective: How individual and institutional investors view money market mutual funds and current regulatory proposals designed to change money funds", February 2012. http://www.sec.gov/comments/4-619/4619-116.pdf

Kacperczyk and Schnabl, “The Risk-Taking Incentives of Money Market Funds,” February 2012. http://economics.mit.edu/files/7588

McCabe, Patrick E., “The Cross Section of Money Market Fund Risks and Financial Crises,” Federal Reserve Board Working Paper 2010-51. http://federalreserve.gov/pubs/feds/2010/201051/201051pap.pdf

Moody’s report, “Sponsor Support Key to Money Market Funds”, August 2010.

http://www.moodys.com/researchdocumentcontentpage.aspx?docid=PBC 126231 


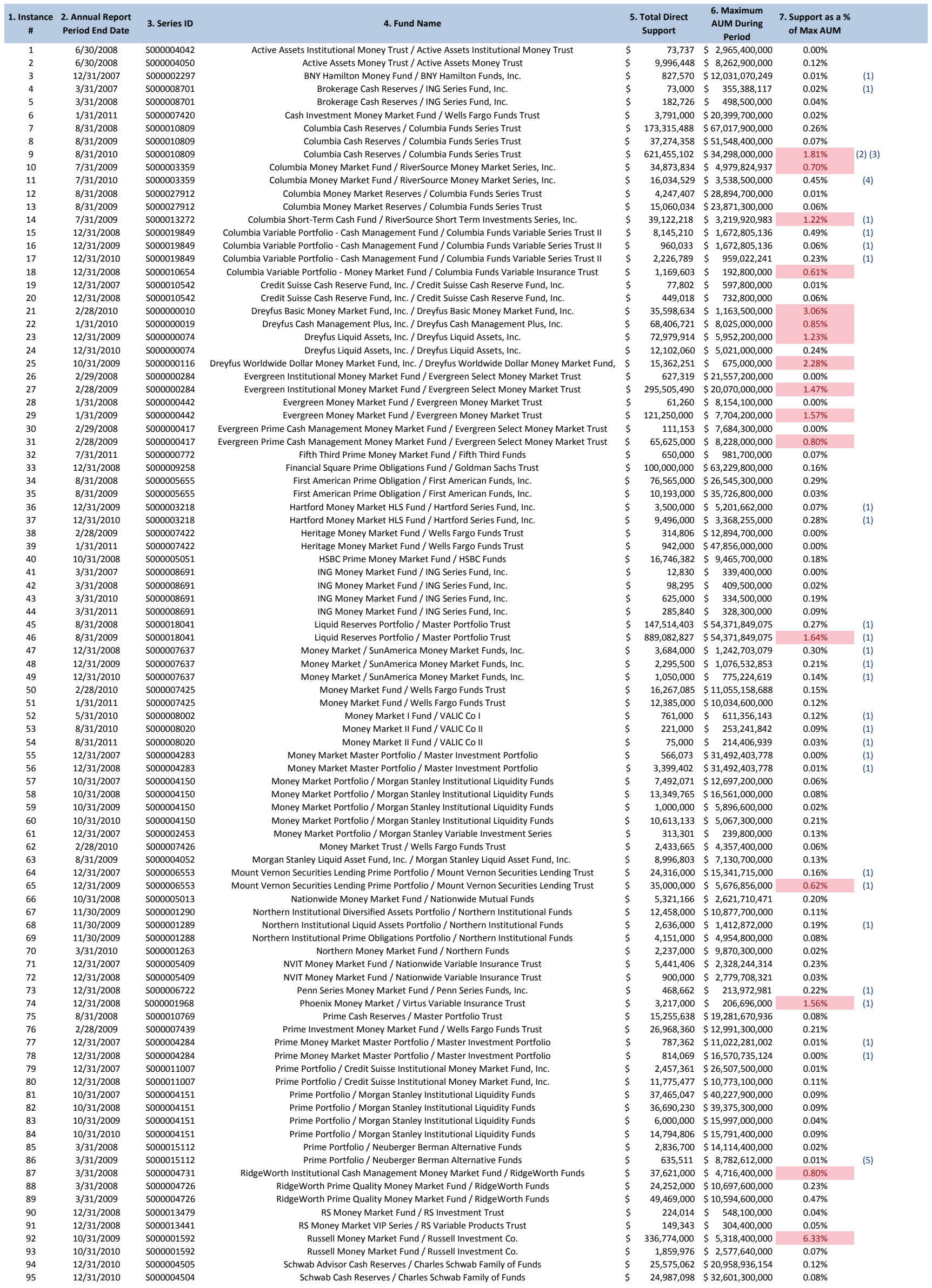




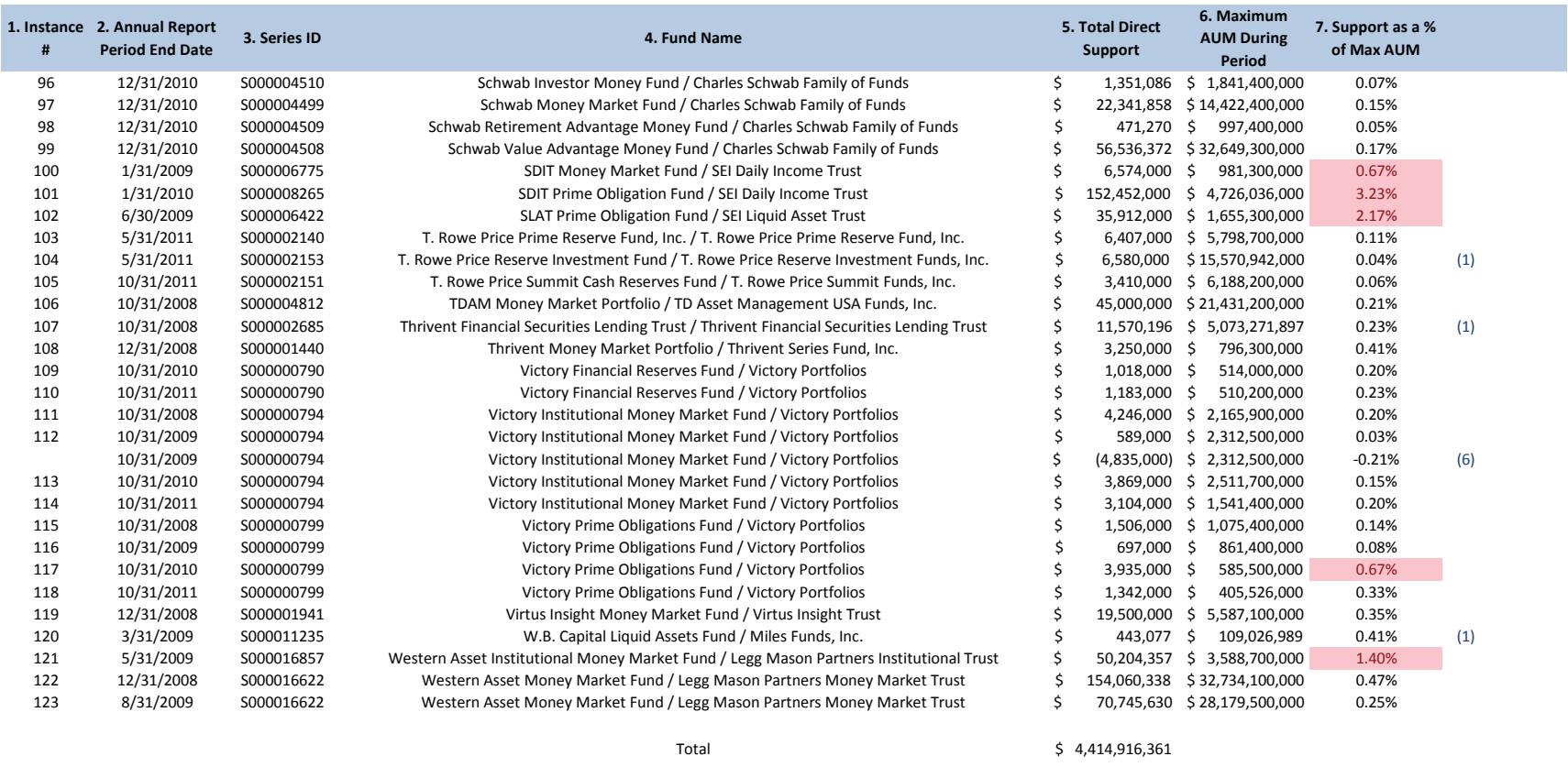

Footnotes:

(1) iMoneyNet data unavailable or incomplete for this fund for this period.

(2) This support amount includes $\$ 21,755,102$ disclosed as a capital contribution. Also included is the authors' estimate of the difference between the purchase price and market value of purchases of defaulted $\$ 599.7$ million at August 31,2009 and terminated effective October 8,2009 .

(3) Columbia Cash Reserves / Columbia Funds Series Trust became the Bank of America Cash Reserves / Bank of America Fund Series Trust with the Series ID, S000027908, in 2010. The Columbia Cash Reserves Series ID has been used for consistency in the data set.

(4) RiverSource Cash Management Fund / River source Money Market Series, Inc. was renamed the Columbia Money Market Fund/RiverSource Money Market Series in 2010 and retained the same series ID.

5) Maximum AUM for this instance is beginning of period AUM. Direct support occurred on April 29, 2008 and was reported as a subsequent event on the Fund's financial statement ended March 31, 2008. On September 28, 2008, the Fund converted from a "master-feeder" structure to a single-tier structure. As a result of the conversion, we deemed subsequent AUM data incomparable.

(6) This represents a return of support to the sponsor and is not counted as an instance. 


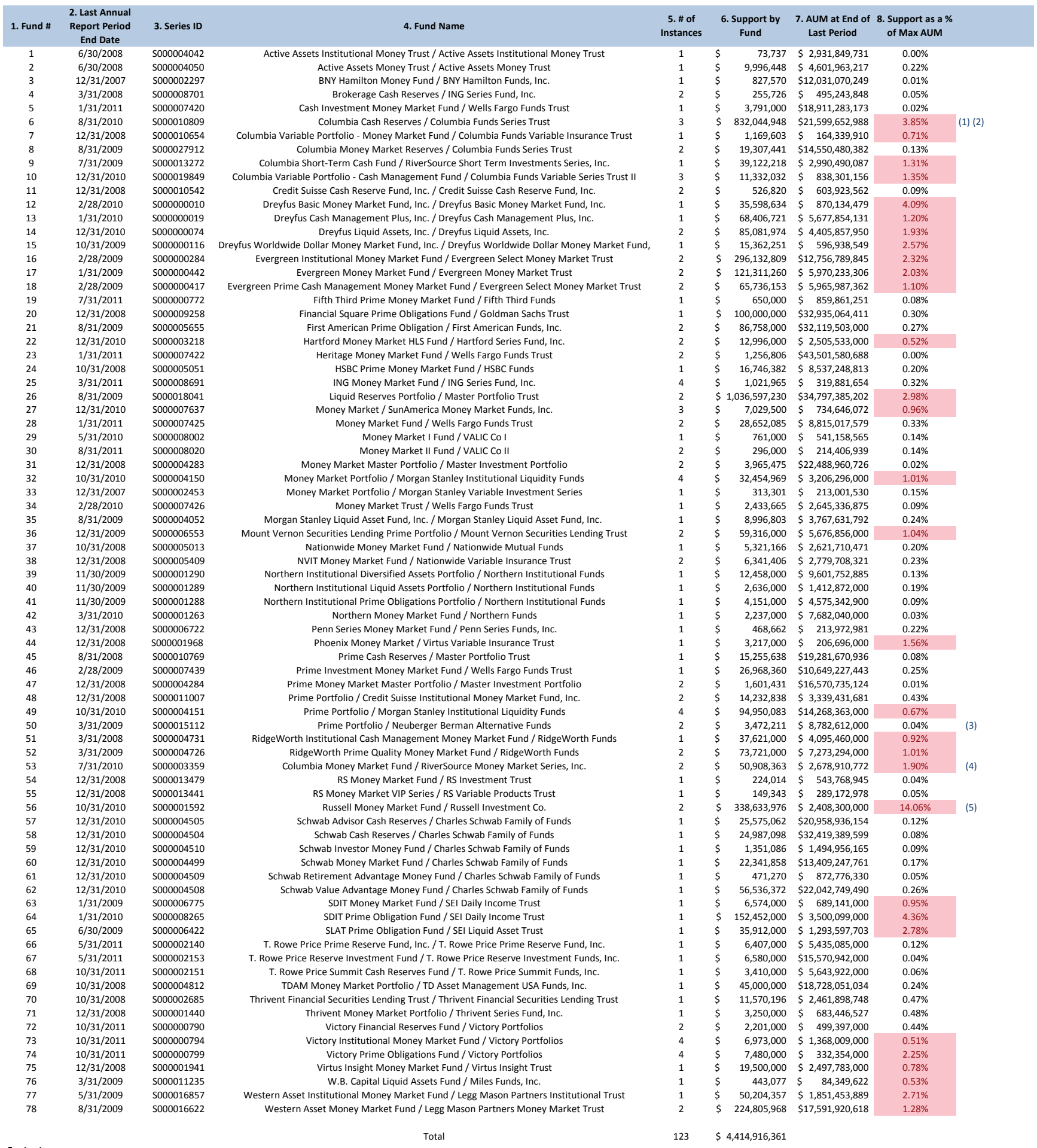

Footnotes:

(1) Total includes an estimate of the difference between the purchase price and market value of purchases of defaulted securities during the 2010 fiscal year for $\$ 1,249$ million for which no market value was disclosed. The estimated excess of the purchase price over fair market value is based on the change in the value of the Capital Support Agreement, which was \$599.7 million at August 31, 2009 and terminated effective October 8, 2009.

(2) Columbia Cash Reserves / Columbia Funds Series Trust became the Bank of America Cash Reserves / Bank of America Fund Series Trust with the Series ID, S000027908, in 2010. The Columbia Cash Reserves Series ID has been used for consistency in the data set.

(3) Ending AUM for this Fund is beginning of period AUM. Direct support occurred on April 29, 2008 and was reported as a subsequent event on the Fund's financial statement ended March 31, 2008. On September 28, 2008, the Fund converted from a "master-feeder" structure to a single-tier structure. As a result of the conversion, we deemed subsequent AUM data incomparable.

(4) RiverSource Cash Management Fund / RiverSource Money Market Series, Inc. was renamed the Columbia Money Market Fund/RiverSource Money Market Series in 2010 and retained the same series ID.

(5) Due to a change in the collateral investment strategy of Russell funds that participate in securities lending activities (as described in the fund prospectus amended November 18,2009 ) significant assets invested in this Fund were reallocated to other Russell funds in November 2009. Accordingly, ending AUM of $\$ 339$ million for the last period is not deemed a relevant measure. As such iMoneyNet AUM data as of November 2, 2009 of $\$ 2.4$ billion was substituted for "AUM at End of Last Period". 
Figure 3

Defaulted Securities in 2007 and 2008 Held by Prime MMMFs

- Axon Financial Funding LLC

- Cheyne Finance LLC/Gryphon Funding LLC/SIV Portfolio LLC

- Lehman Brothers Holdings Inc.

- $\quad$ Orion Finance LLC

- Ottimo Funding Ltd./Issuer Entity LLC

- Stanfield Victoria Funding LLC / Victoria Finance LLC

- Thornburg Mortgage Capital Resources LLC/ Wickersham Entity LLC

- Whistlejacket Capital LLC 
Figure 4

Disclosed Reason for Support for Instances Representing Over 0.5\% of AUM

\begin{tabular}{llc}
\hline & \multicolumn{1}{c}{$\begin{array}{c}\text { Disclosed Reason for Support } \\
\text { (sourced directly from N-CSR filings, unless otherwise noted) }\end{array}$} & $\begin{array}{c}\text { \# of } \\
\text { Instances }\end{array}$ \\
\hline 1 & Lehman & 8 \\
& $\begin{array}{l}\text { Some combination of two or more of the following } \\
\text { structured investment vehicles: Axon, Cheyne, Gryphon, } \\
\text { Issuer, Orion, Ottimo, Victoria, Wickersham, Whistlejacket }\end{array}$ & 6 \\
& $\begin{array}{l}\text { Lehman and at least one of the structured investment } \\
\text { vehicles on line } 2\end{array}$ & 2 \\
\hline 4 & $\begin{array}{l}\text { Morgan Stanley and “Securities” } \\
\text { International Lease Finance Corporation, a subsidiary of }\end{array}$ & 2 \\
\hline 5 & $\begin{array}{l}\text { AIG* } \\
\text { Cheyne** }\end{array}$ & 1 \\
\hline 7 & $\begin{array}{l}\text { "Loss recovery payments for difference between amortized } \\
\text { cost and market value” }\end{array}$ & 1 \\
\hline
\end{tabular}

*This support reason was not specifically disclosed in the N-CSR filing, but rather was cited by the fund in a no action letter filed on the date of support disclosed in the N-CSR.

**This support reason was not noted in the N-CSR filing of the instance, which only cited contributions "to maintain the mark-to market net asset value," but was noted in prior period N-CSR filings. 